\title{
ПРЕДОТВРАЩЕНИЕ РАЗВИТИЯ НАЧАЛЬНЫХ ПРИЗНАКОВ ВЕНОЗНОЙ НЕДОСТАТОЧНОСТИ, СВЯЗАННОЙ С ИНТРАОПЕРАЦИОННЫМ ПОВРЕЖДЕНИЕМ БОЛЬШОЙ ПОДКОЖНОЙ ВЕНЫ ПРИ ОПЕРАТИВНОМ ЛЕЧЕНИИ ПЕРЕЛОМОВ ЛОДЫЖЕК И ГОЛЕНИ
}

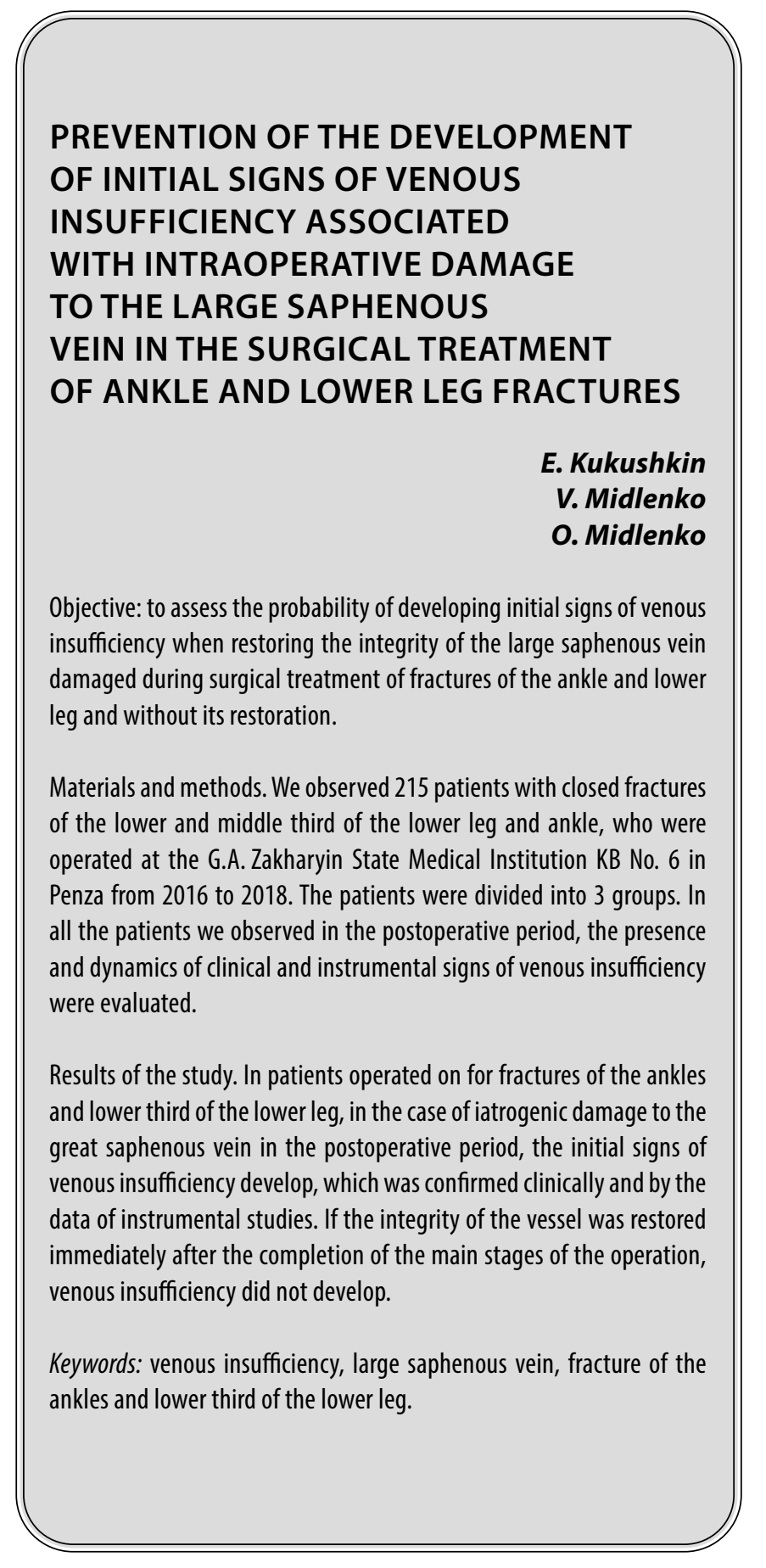

\author{
Кукушкин Евгений Петрович \\ Аспирант, Ульяновский Государственный \\ Университет; Врач травматолог-ортопед, врач \\ ультразвуковой диагностики, ГБУз клиническая \\ больница № 6 имени Г.А. Захарьина, г. Пенза \\ kep131289@gmail.com \\ Мидленко Владимир Ильич \\ Заслуженный работник высшей школы $Р Ф$, \\ директор, Институт медицины, экологии \\ и физической культуры; д.м.н., профессор, Ульяновский \\ государственный университет \\ Мидленко Олег Владимирович \\ Директор, Инзенский филиал Ульяновского \\ государственного университета; профессор, \\ Ульяновский государственный университет
}

Аннотация. Цель исследования: оценить вероятность развития начальных признаков венозной недостаточности при восстановлении целостности большой подкожной вены, поврежденной при оперативном лечении переломов лодыжки и голени и без ее восстановления.

Материалы и методы. Наблюдали 215 пациентов с закрытыми переломами нижней и средней трети голени и лодыжки, которые были оперированы в ГБУЗ КБ № 6 им. Г.А. Захарьина г. Пенза с 2016 по 2018 гг. Пациенты были разделены на 3 группы. У всех наблюдавшихся нами пациентов в послеоперационном периоде оценивались наличие и динамика клинических и инструментальных признаков венозной недостаточности.

Результаты исследования. У пациентов, оперированных по поводу переломов лодыжек и нижней трети голени, в случае ятрогенного повреждения большой подкожной вены в послеоперационном периоде развиваются начальные признаки венозной недостаточности, что подтверждалось клинически и данными инструментальных исследований. Если целостность сосуда восстанавливалась сразу после завершения основных этапов операции, венозная недостаточность не развивалась.

Ключевые слова: венозная недостаточность, большая подкожная вена, перелом лодыжек и нижней трети голени. 


\section{Ввемение}

B большинстве случаев травматологические операции, выполняемые на нижних конечностях, при переломах лодыжек, нижней и средней трети голени, в силу анатомических особенностей зоны вмешательства, создают условия для ятрогенного повреждения большой подкожной вены в месте, где она проходит около внутренней лодыжки. [14, с. 417]. В настоящее время травматологи практически не придают этому значения и при повреждении большой подкожной вены ограничиваются гемостазом, путём ее перевязки [9]. Это неизбежно приводит к нарушению кровотока и развитию начальных признаков венозной недостаточности нижней конечности. В этом случае, при хорошей консолидации перелома и отсутствии серьёзных проблем со стороны костной системы, у пациентов все же ухудшается качество жизни из-за развивающейся венозной недостаточности нижней конечности. [3]. Поэтому, представляется целесообразным уделять внимание профилактике ятрогенных повреждений большой подкожной вены. С точки зрения специалистов, располагающих опытом хирургического лечения пациентов, перенесших ятрогенную травму сосудов, нельзя ограничиваться только констатацией факта возникновения сосудистого осложнения и остановкой кровотечения, в современных условиях необходимо стремиться к восстановлению целостности поврежденного сосуда. $[5,8,11]$.

\section{Актуальность проблемы}

В доступной для изучения литературе, как отечественных, так и зарубежных авторов, в настоящее время недостаточно раскрыта проблема развития начальных признаков венозной недостаточности нижних конечностей после интраоперационного повреждения большой подкожной вены при операциях по поводу закрытых переломов нижней трети голени и внутренней лодыжки. [12,16]. Безусловно, роль подкожных вен (совместно малой и большой) в оттоке крови от нижних конечностей составляет не более $10 \%$, и основной путь возврата крови осуществляется по глубоким венам. Также установлено, что основной причиной развития хронической венозной недостаточности при переломах костей нижних конечностей следует считать развитие тромбоза глубоких вен нижних конечностей с формированием посттромботической болезни $[13,15]$. Основной, но не единственной. В связи с этим, в нашей работе акцент сделан на 10\% изменений в поверхностных венах, роль которых, как нам кажется, недооценена.

\section{Шель исслеАования}

Оценить вероятность развития начальных признаков венозной недостаточности при восстановлении целостности большой подкожной вены, поврежденной при оперативном лечении переломов лодыжки и голени и без ее восстановления.

\section{Материалы и метолы}

Тип проводимого исследования: аналитическое.

Мы наблюдали 215 пациентов с закрытыми переломами нижней и средней трети голени и лодыжки, которые были оперированы в клинической больнице № 6 им. Г.А. Захарьина, города Пенза в период с 2016 по 2018 гг. в возрасте от 18 до 89 лет (54 235 лет). Соотношение мужчин и женщин было: $55 \%$ и $45 \%$ соответственно.

Критериями исключения из исследования были наличие открытых травм, консервативное ведение пациентов, имеющиеся признаки венозной недостаточности или посттравматические тромбозы вен нижних конечностей. Всем пациентам в предоперационном периоде выполнялось ультразвуковое исследование сосудов нижних конечностей с целью оценки скорости кровотока и проходимости по глубоким и перфорантным венам, а также с целью исключения тромбов. $[6,10]$. Все пациенты получали комплекс мероприятий согласно протоколу профилактики тромбообразования.

В первой, ретроспективной, группе сравнения были

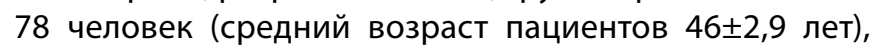
у которых произошло интраоперационное повреждение большой подкожной вены.

Вторую группу (контрольную) сравнения составили

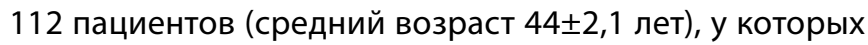
во время операции не было повреждения большой подкожной вены, в основном при использовании авторских методик.

Третья, группа составлена из 25 пациентов (средний

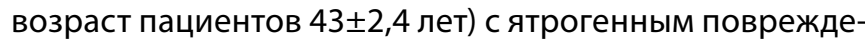
нием большой подкожной вены во время операции, но целостность сосуда была восстановлена путём наложение сосудистого шва.

У всех наблюдавшихся нами пациентов в послеоперационном периоде оценивались наличие и динамика клинических признаков венозной недостаточности, к которым относятся появление сосудистых звездочек, ночные мышечные судороги, отеки стопы и голени, утомляемость ног. Всем пациентам проводились стандартные лабораторные исследования, в том числе исследование свертывающей системы крови. Продолжались профилактические мероприятия по предотвращению образования тромбов. С целью объективизации 
данных пациентам проводилось ультразвуковое исследование венозной системы нижних конечностей с помощью аппарата Medison SonoAcex 8.

Изначальное отсутствие признаков венозной недостаточности подтверждалось клинически и данными ультразвукового исследования. На уровне нижней трети голени, на 5 см выше внутренней лодыжки оценивались диаметр большой и малой подкожных вен здоровой и повреждённой конечностей и скорость кровотока по указанным сосудам, также оценивалась проходимость глубоких и поверхностных вен.

Ни у одного из наблюдавшихся пациентов не было признаков наличия тромбов глубоких вен.

Оперативное лечение проводилось под спинальным обезболиванием. Операция выполнялась в объёме восстановления анатомического соотношения костных структур с фиксацией металлоконструкциями. Восстановление повреждённой большой подкожной вены проводилось после завершения основных этапов операции путем сшивания конец в конец, при выраженном отёке тканей в 9 случаях потребовалась мобилизация сосуда на небольшом протяжении.

В послеоперационном периоде, во время нахождения пациентов в стационаре при ежедневных осмотрах оценивались жалобы, характеристики кожных покровов, измерялись окружности в области голеностопного сустава, нижней трети голени и стопы, ультразвуковое исследование. При ультразвуковом исследовании сосудов нижних конечностей, как поверхностных, так и глубоких вен, у пациентов в послеоперационном периоде (на 1-й день после операции, на 3-й день и за день до выписки) отмечалось отсутствие каких-либо достоверно подтвержденных изменений в глубоких венах, хотя изменения в поверхностных венах были уже заметны.

Статистический анализ полученных данных проводили с применением программы Statistica 6,0. Bce данные приведены в виде средних арифметических значений и их стандартного отклонения $(\mathrm{M} \pm \mathrm{m})$. Статистический анализ осуществляли с помощью t-критерия Стьюдента для данных с нормальным распределением. Для сравнения дискретных величин применяли непараметрические критерии: для несвязанных выборокпарный критерий Манна-Уитни, для связанных - критерий Уилкоксона. Достоверность коэффициентов различий принимали при значении $\mathrm{p}<0,05$. [1].

\section{Результаты исслеАования}

У пациентов, оперированных по поводу переломов лодыжек и нижней трети голени в случае ятрогенного повреждения большой подкожной вены в послеоперационном периоде развиваются начальные признаки венозной недостаточности, что подтверждалось клинически и данными инструментальных исследований. У пациентов с интраоперационным повреждением большой подкожной вены отмечалось увеличение ее диаме-

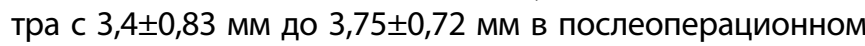

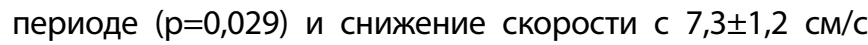
до $6,9 \pm 0,96 \mathrm{~cm} / \mathrm{c}(p=0,034)$ при восстановлении сосуда, вплоть до полного отсутствия кровотока при повреждении сосуда, без восстановления скорости кровотока. Менялся диаметр малой подкожной вены, увеличиваясь

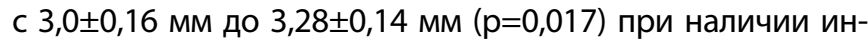
траоперационного повреждения, при отсутствии интраоперационного повреждения большой подкожной вены

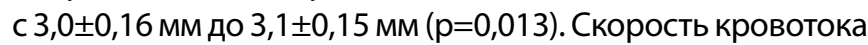
в малой подкожной вене менялась не столь значительно: от $2,8 \pm 0,17 \mathrm{~cm} /$ с до $3,0 \pm 0,12 \mathrm{~cm} / \mathrm{c}(\mathrm{p}=0,018)$ соответственно.

В первой группе сравнения самой частой жалобой была отмечена быстрая утомляемость $(61,2 \%)$. Ночные судороги беспокоили 38,8\% пациентов. Отёчность конечности отмечали 20,4\% больных, у 12,6\% появились «сосудистые звёздочки». Увеличение окружности голени, стопы и области голеностопного сустава определялось у $90,3 \%$ пациентов.

Анализ данных пациентов второй группы сравнения (контрольной) показал, что статистически достоверных отличий с предыдущей группой в части болевого синдрома не было: 3,88\% в первой группе и 3,74\% во второй группе соответственно ( $p=0,0354)$. Но в части признаков венозной недостаточности картина была совершенно другая. Так, отёчность конечности отмечали только 8,4\% пациентов, а такие показатели, как быстрая утомляемость, ночные судороги и появление «сосудистых звёздочек» во второй контрольной группе не отмечались.

Показатели пациентов третьей группы в послеоперационном периоде, не имели статистически значимых отличий от показателей второй контрольной группы.

\section{Данные представлены в таблице 1.}

Анализируя полученные данные, при повреждении большой подкожной вены интраоперационно, без ее восстановления, начальные признаки хронической венозной недостаточности развиваются в среднем в $33,3 \%$ случаев.

Восстановление целостности сосуда во время операции приводит к развитию начальных признаков хронической венозной недостаточности в среднем в $2,4 \%$ случаев, что в 14 раз меньше, если сосуд не восстанавливать (1 группа сравнения). $\mathrm{P}=0,039$ 
Таблица 1. Оценка жалоб пациентов в зависимости от хода операции

\begin{tabular}{|l|l|l|l|l|l|}
\multirow{2}{*}{ Жалобы пациентов } & \multicolumn{2}{|l}{$\begin{array}{l}\text { Процент выявления (\%) } \\
\text { в изучаемых группах }\end{array}$} & $\begin{array}{l}\text { 3 группа } \\
\text { (С повреждением БПВ) } \\
\text { (С повреждением } \\
\text { БПВ, восстановлением } \\
\text { хода сосуда) }\end{array}$ & $\begin{array}{l}\text { 2 группа (Без } \\
\text { повреждения БПВ)-2 } \\
\text { контрольная }\end{array}$ & P 1-3 \\
\hline $\begin{array}{l}\text { «сосудистые } \\
\text { звездочки» }\end{array}$ & - & - & 0,0274 & 0,0313 \\
\hline утомляемость & 12,6 & - & 1,2 & 0,0134 & 0,0505 \\
\hline ночные судороги & 31,2 & - & - & 0,0276 & 0,0456 \\
\hline отечность ног & 20,4 & 8,41 & 8,39 & 0,0751 & 0,0795 \\
\hline $\begin{array}{l}\text { боль в области } \\
\text { переломов }\end{array}$ & 3,88 & 3,74 & 3,75 & 0,0458 & 0,0598 \\
\hline $\begin{array}{l}\text { ограничение } \\
\text { движений }\end{array}$ & - & 15,9 & - & 0,0739 & 0 \\
\hline
\end{tabular}

Таблица 2. Показатели венозной системы (скорость кровотока и диаметр сосуда) после операции при переломах лодыжек без интраоперационного повреждения и при ятрогенном интраоперационном повреждении большой подкожной вены

\begin{tabular}{|c|c|c|c|c|c|c|}
\hline \multirow[b]{2}{*}{ Вены } & \multirow[b]{2}{*}{ Показатели } & \multicolumn{5}{|c|}{ Состояние после операции } \\
\hline & & $\begin{array}{l}1 \text { группа } \\
n=78\end{array}$ & $\begin{array}{l}2 \text { группа } \\
\text { n=112 }\end{array}$ & P 1-2 & $\begin{array}{l}3 \text { группа } \\
n=25\end{array}$ & P 1-3 \\
\hline \multirow{2}{*}{ МПВ } & Диаметр, мм & $3,28 \pm 0,13$ & $3,0 \pm 0,16$ & 0,037 & $3,1 \pm 0,18$ & 0,039 \\
\hline & Скорость, см/C & $2,8 \pm 0,17$ & $3,1 \pm 0,9$ & 0,028 & $3,0 \pm 0,12$ & 0,024 \\
\hline \multirow{2}{*}{ БПВ } & Диаметр, мм & $3,9 \pm 0,56$ & $3,64 \pm 0,89$ & 0,023 & $3,75 \pm 0,13$ & 0,029 \\
\hline & Скорость, см/C & Отсутствует & $7,3 \pm 0,23$ & 0,049 & $6,8 \pm 0,96$ & 0,023 \\
\hline
\end{tabular}

МПВ - малая подкожная вена

БПВ - большая подкожная вена

Таблица 3. Показатели венозной системы (скорость кровотока и диаметр сосуда) после операции при переломах н/3 голени без интраоперационного повреждения и при ятрогенном интраоперационном повреждении большой подкожной вены

\begin{tabular}{|c|c|c|c|c|c|c|}
\hline \multirow[b]{2}{*}{ Вены } & \multirow[b]{2}{*}{ Показатели } & \multicolumn{5}{|c|}{ Состояние после операции } \\
\hline & & 1 группа n=78 & $\begin{array}{l}2 \text { группа } \\
n=112\end{array}$ & P 1-2 & $\begin{array}{l}3 \text { группа } \\
\mathrm{n}=25\end{array}$ & P 1-3 \\
\hline \multirow{2}{*}{ МПВ } & Диаметр, мм & $3,28 \pm 0,15$ & $3,1 \pm 0,13$ & 0,039 & $3,16 \pm 0,14$ & 0,040 \\
\hline & Скорость, см/с & $2,8 \pm 1,3$ & $3,1 \pm 0,88$ & 0,028 & $3,0 \pm 1,11$ & 0,024 \\
\hline \multirow{2}{*}{ БПВ } & Диаметр, мм & $3,75 \pm 0,72$ & $3,4 \pm 0,83$ & 0,019 & $3.64 \pm 0,11$ & 0,025 \\
\hline & Скорость, см/с & отсутствует & $7,3 \pm 1,4$ & 0,049 & $6,9 \pm 0,96$ & 0,024 \\
\hline
\end{tabular}

МПВ - малая подкожная вена

БПВ - большая подкожная вена

Также мы проводили сравнение у пациентов с разной локализацией переломов.

Данные приведены в таблицах 2,3.

При ультразвуковом исследовании установлено, что статистически достоверные различия показателей кровотока (диаметр сосуда и скорость кровотока) были только при сравнении между первой и второй исследуемой группами и не зависели от локализации перелома.

В первой группе исследования (повреждение большой подкожной вены интраоперационно) кровоток 
в большой подкожной вене на уровне голеностопного сустава полностью отсутствовал, а во второй и третьей группах сохранялся. Диаметр большой подкожной

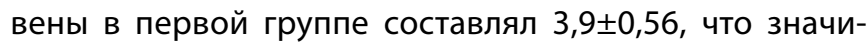
тельно отличалось при ультразвуковом исследовании во второй и третьей группах на уровне голеностопного сустава, где он уменьшался до $3,64 \pm 0,89(p=0,023)$ и 3,75 $\pm 0,13(p=0,029)$ соответственно. При увеличении диаметра сосуда в наблюдаемых случаях гемодинамических нарушений не наблюдалось.

В первой группе исследования кровоток в большой подкожной вене на уровне н/3 голени полностью отсутствовал, а во второй и третьей группах сохранялся. При восстановлении целостности сосуда (третья группа исследования) изменения были гемодинамически незначимыми: скорость кровотока уменьшалась с 7,3 1,4 $(p=0,049) \mathrm{cm} /$ д до $6,9 \pm 0,96 \mathrm{~cm} / \mathrm{c}(\mathrm{p}=0,024)$ по сравнению с контрольной второй группой. У пациентов с интраоперационным повреждением большой подкожной вены в послеоперационном периоде отмечалось увеличе-

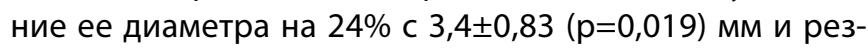
кое снижение скорости кровотока. Менялся диаметр

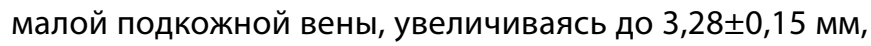
против $3,1 \pm 0,13$ ( $p=0,039)$ мм при отсутствии интраоперационного повреждения большой подкожной вены. Скорость кровотока в малой подкожной вене менялась не столь значительно, увеличиваясь с 2,8 21,3 в первой группе до $3,1 \pm 0,13(p=0,039)$ во второй группе и 3,16 $\pm 0,14(p=0,040)$ в третьей группе. Данные ультразвукового исследования в послеоперационном периоде у пациентов с интраоперационным повреждением большой подкожной вены, если целостность сосуда восстанавливалась во время первичной операции, статистически достоверно не отличались (таблицы № 2 и № 3) от данных пациентов второй контрольной группы (диаметр уменьшался на 11,1\% ( $<<0,05)$, а скорость кровотока возрастала на 8,9\% $(\mathrm{p}<0,05)$ при переломах лодыжек; диаметр уменьшался на 14,3\% (p<0,05), а скорость кровотока возрастала на $8,6 \%(p<0,05)$ при переломах н/3 голени).

\section{Обсужление}

Из литературных источников известно, что при травмах нижних конечностей возрастает угроза тромботических осложнений и в 80-90\% случаев причиной развития венозной недостаточности нижних конечностей после травмы указываются тромбозы глубоких вен. [2]. Согласно данным статьи из Ивановской Государственной медицинской академии, изменения венозного русла, приводящие к нарушению оттока крови, а как следствие и к развитию начальных признаков венозной недостаточности в 51,4\% случаев является патология глубокого венозного русла и в $24,3 \%$ случаев - тромбоз глубоких вен [4]. Остальные 15-25\% случаев до конца еще не изучены. Нашей работой мы хотели показать, что интраоперационное повреждение большой подкожной вены, при отсутствии тромбоза или каких-либо других гемодинамически значимых изменений со стороны глубоких вен, также может привести к развитию начальных признаков венозной недостаточности.

Современный уровень профилактики тромботических осложнений позволяет их предотвратить [7]. Подтверждается это тем, что при исследовании пациентов с травмами нижних конечностей, в лечении которых применялась специфическая и неспецифическая профилактика, а также авторские методики, направленные на предотвращение повреждения большой подкожной вены во время операции, тромбозов не наблюдалось. Исходя из вышеизложенного, мы считаем, что причиной развития венозной недостаточности являлось ятрогенное повреждение большой подкожной вены во время травматологических операций.

\section{Выво $ы$ по представленной работе}

1. Интраоперационное ятрогенное повреждение большой подкожной вены, при отсутствии предоперационных признаков тромбоза или каких-либо других гемодинамически значимых изменений со стороны глубоких, а также поверхностных вен, может привести к развитию начальных признаков венозной недостаточности в 33,3\% случаев (из них: появление «сосудистых звездочек» $12,6 \%$, быстрой утомляемости ног в $61,2 \%$, ночных судорог $38,8 \%$, отечности ног в 20,4\%)

2. Не устранённое ятрогенное повреждение большой подкожной вены при операции по поводу переломов лодыжек и нижней трети голени в 33,3\% может привести к развитию начальных признаков венозной недостаточности (появление «сосудистых звездочек», быстрой утомляемости ног, ночных судорог, отечности ног) в послеоперационном периоде

3. В нашей работе показано, что незамедлительное восстановление целостности, повреждённой во время операции большой подкожной вены, может снизить риск развития начальных признаков венозной недостаточности в 97,6\% в послеоперационном периоде у пациентов, оперированных по поводу переломов лодыжек и нижней трети голени. В нашем исследовании, развитие начальных признаков венозной недостаточности при восстановлении целостности большой подкожной вены, поврежденной при оперативном лечении переломов лодыжки и голени, составляет $2,4 \%$. 


\section{ЛИТЕРАТУРА}

1. Алиев М.Х., Мамедзаде А.Я., Агамалыева У.Д., Шахвердиев Г.Г., Алиева Д.Т., Гаджиева С.И. Эндотелиальная дисфункция и нарушение лимфатического дренажа сердца в патогенезе кардиоваскулярных осложнений сахарного диабета. // Казанский медицинский журнал. — 2020. № 1- С. 47-52.

2. Венозные тромботические осложнения при травмах нижних конечностей и эндопротезировании тазобедренного и коленного суставов / Н.Ю. Матвеева, Н.А. Еськин, 3.Г. Нацвлишвили, Л.К. Михайлова // Вестник травматологии и ортопедии им. Н.Н. Приорова. — 2002. № 1.— C. 85

3. Ветшев П.С., Крылов Н.Н., Шпаченко Ф.А. Изучение качества жизни пациентов после хирургического лечения // Хирургия, 2000. № 1.— С. 64-67.

4. Гавриленко А.В., Вахратьян П.Е. Хирургическое лечение начальных форм варикозного расширения вен нижних конечностей // Хирургия, 2005. № 4. - C. 42-44

5. Значение различных методов реконструктивной сосудистой и микрососудистой хирургии в онкологии / М.И. Давыдов [и др.] // Вопросы онкологии. - 2005.- Т. 51. - № 3. С. 311-313.

6. Зубарев А.Р., Неменова Н.А. Ультразвуковое исследование опорно-двигательного аппарата у взрослых и детей: Пособие для врачей, 一 М.: Издательский дом Видар-М, 2006. - 136 с.

7. Измайлов С.Г., Измайлов Г.А., Аверьянов М.Ю. и др. Хирургические технологии в лечении варикозного расширения вен нижних конечностей //Хирургия. 2002. - № 1.- С. 10-15

8. Князев М.Д. Ятрогенные повреждения магистральных кровеносных сосудов. / М.Д. Князев, И.А. Комаров, В.Я. Киселев. // Хирургия. Журн. им. Н.И. Пирогова — 1985. - № 12. С. 85-87.

9. Лохвицкий С.В. Повреждения магистральных вен во время операций. / С.В. Лохвицкий, С.И. Токпанов // Вестник хирургии им. И.И. Грекова 1981. — № 4.—C. 118-120

10. Методика дуплексного сканирования вен нижних конечностей// Учебное пособие// Е.В. Осипова, Л.В. Мельникова, А.В. Крылова// 2010 г.

11. Миначенко В.К. Ятрогенные повреждения магистральных сосудов / В.К. Миначенко // Советская медицина. — 1986.— № 10.—C. $102-105$.

12. Писарев В.В. Особенности антеградного кровотока и венозные тромботические осложнения у больных с переломами костей голени и бедра/ В.В. Писарев, С.Е. Львов, 0.И. Кутрева, О.С. Молчанов // Травматология и ортопедия России. — 2009. — № 2. — С. 33-38.

13. Практикум по лечению варикозной болезни. / Под ред. Г.Д. Константиновой. — М; Профиль, — 2006. - С. 188.

14. Синельников Р.Д. Атлас анатомии человека. Издание пятое. перераб. и доп. - М.: Медицина, 1972.-Т.2. — С. 417.

15. Швальб П.Г. Системный подход к патогенезу хронической венозной недостаточности нижних конечностей // Ангиология и сосудистая хирургия.2002.-T.8, № 3.-С.30-36.

16. Kachlik D., Pechacek V., Baca V., Musil V. The superficial venous system of the lower extremity: new nomenclature. // Phlebology -2010-113-123.

( К Кукушкин Евгений Петрович ( kep131289@gmail.com ),

Мидленко Владимир Ильич, Мидленко Олег Владимирович.

Журнал «Современная наука: актуальные проблемы теории и практики» 